\title{
Letter
}

\section{Suzuki Coupling Approach for the Synthesis of Phenylene-Pyrimidine Alternating Oligomers for Blue Light-Emitting Material}

Ken-Tsung Wong, Tsung Shi Hung, Yuting Lin, Chung-Chih Wu, Gene-Hsiang

Lee, Shie-Ming Peng, Chung Hsien Chou, and Yuhlong Oliver Su

Org. Lett., 2002, 4 (4), 513-516• DOI: 10.1021/ol017066z • Publication Date (Web): 31 January 2002

Downloaded from http://pubs.acs.org on February 17, 2009

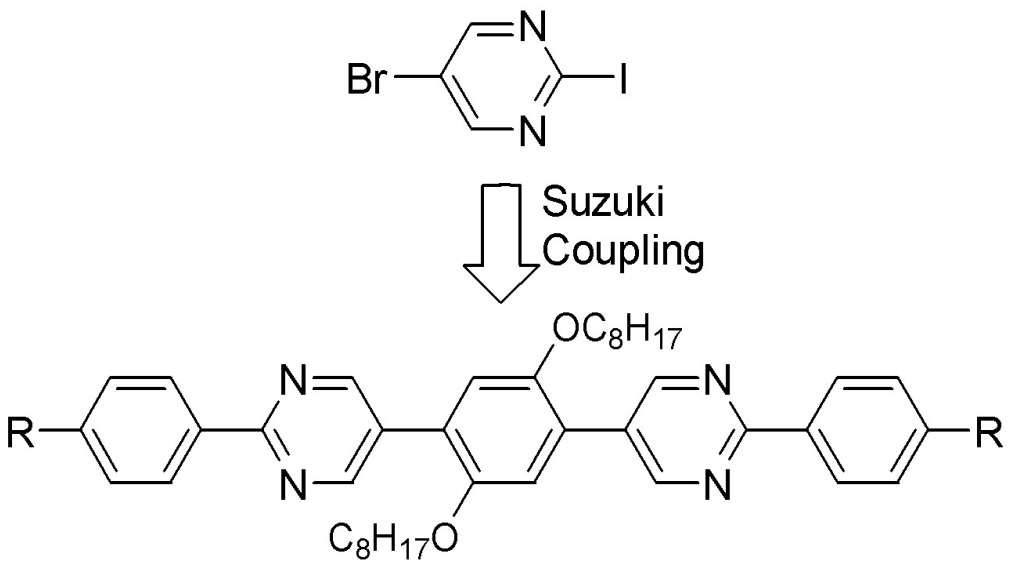

\section{More About This Article}

Additional resources and features associated with this article are available within the HTML version:

- Supporting Information

- $\quad$ Links to the 5 articles that cite this article, as of the time of this article download

- Access to high resolution figures

- $\quad$ Links to articles and content related to this article

- $\quad$ Copyright permission to reproduce figures and/or text from this article

\section{View the Full Text HTML}




\section{Suzuki Coupling Approach for the Synthesis of Phenylene-Pyrimidine Alternating Oligomers for Blue Light-Emitting Material}

2002

Vol. 4, No. 4

$513-516$

\section{Ken-Tsung Wong, ${ }^{*}, \dagger$ Tsung Shi Hung, ${ }^{\dagger}$ Yuting Lin, ${ }^{\ddagger}$ Chung-Chih Wu, ${ }^{*}, \neq$ Gene-Hsiang Lee, ${ }^{\dagger}$ Shie-Ming Peng, ${ }^{\dagger}$ Chung Hsien Chou, ${ }^{\dagger}$ and Yuhlong Oliver Su ${ }^{\dagger}$}

Department of Chemistry and Graduate Institute of Electro-Optical Engineering, National Taiwan University, Taipei 106, Taiwan

kenwong@ccms.ntu.edu.tw

Received November 19, 2001

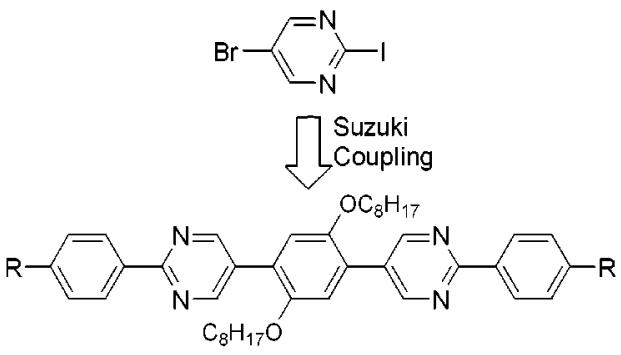

Conjugated oligomers with an alternating phenylene-pyrimidine structure have been synthesized by the successive Suzuki coupling reaction starting from 2-bromo-5-iodopyrimidine. The photoluminescence properties and quasi-reversible redox behavior of these oligomers make them applicable as an active material for a light-emitting device. Blue light-emitting electroluminescent devices with an external quantum efficiency up to $1.8 \%$ have been fabricated.

Since the pioneering work ${ }^{1}$ of Tang and VanSlyke in the thin film OLED device, conjugated organic materials with high morphological stability have received considerable attention due to their promising potential for the industrial manufacture of light-emitting displays. ${ }^{2}$ However, most of the organic solids used for OLED exhibit several orders higher of hole mobility than electron mobility. Therefore, the poor quantum efficiency of the OLED device can be primarily ascribed to the imbalance of electron-hole recombination in the active layer. To create an efficient device, new materials with high electron transporting capability are demanded. Over the past decade, many activities have been carried out on this issue, resulting in great contributions to the molecular design for fulfilling the requirements of high

\footnotetext{
Department of Chemistry.

$\doteqdot$ Graduate Institute of Electro-Optical Engineering.

(1) Tang, C. W.; VanSlyke, S. A. Appl. Phys. Lett. 1987, 51, 913.

(2) (a) Kraft, A.; Grimsdale, A. C.; Holmes, A. B. Angew. Chem., Int. Ed. 1998, 37, 402. (b) Shirota, Y. J. Mater. Chem. 2001, 10, 1.
}

electron affinity, high electron mobility, and morphology stability. The electronic properties of organic solids now can be finely tailored by modifying the main chain structure with highly electronegative groups ${ }^{3}$ or introducing the heteroaryl moiety as a functional subunit. For example, 1,3,4-oxadiazole-containing molecules ${ }^{4}$ have been extensively investigated as an electron transporting material in OLED. Moreover, benzimidazole ${ }^{5}$ phenanthroline, ${ }^{6}$ pyridine,${ }^{7}$ pyrazine, ${ }^{8}$ quinoline,${ }^{9}$ quinoxaline,${ }^{10}$ pyrazolopyridine,${ }^{11}$ silole,${ }^{12}$ thiophene-

(3) (a) Moratti, S. C.; Cervini, R.; Holmes, A. B.; Baigent, D. R.; Friend, R. H.; Greenham, N. C.; Grüner, J.; Hamer, P. J. Synth. Met. 1995, 71, 2117. (b) Gómez, R.; Segura, J. L.; Martín, N. Chem. Commun. 1999, 619. (c) Heidenhain, S. B.; Sakamoto, Y.; Suzuki, T.; Miura, A.; Fujikawa, H.; Mori, T.; Tokito, S.; Taga, Y. J. Am. Chem. Soc. 2000, 122, 10240. (e) Uckert, F.; Tak, Y.-H.; Müllen, K.; Bässler, H. Adv. Mater. 2000, 12, 905.

(4) (a) Huang, W.; Meng, H.; Yu, W.-L.; Gao, J.; Heeger, A. J. Adv. Mater. 1998, 10, 593. (b) Chung, S.-J.; Kwon, K.-Y.; Lee, S.-W.; Jin, J.-I.; Lee, C. H.; Lee, C. E.; Park, Y. Adv. Mater. 1998, 10, 1112. (c) Peng, Z.; Zhang, J. Adv. Mater. 1999, 11, 1138.

(5) Tao, Y. T.; Balasubramaniam, E.; Danel, A.; Tomasik, P. Appl. Phys. Lett. 2000, 77, 1575. 
1-oxide, ${ }^{13}$ thiophene-1,1-dioxide, ${ }^{13,14}$ and triazole ${ }^{15}$ have been incorporated into the $\pi$-conjugated systems for improving the electron mobility. Among these heteroaromatics, a pyrimidine-containing molecule is one of the least exploited materials for OLED. Polypyrimidine has been shown to exhibit high electron affinity, ${ }^{16}$ which makes it an attractive candidate for incorporation into a $\pi$-conjugated system. An elegant step-by-step synthetic strategy for the synthesis of pyrimidine-containing oligophenylenes has been reported by Gommper et al. ${ }^{17}$ We report in this Letter a new approach for the synthesis of phenylene-pyrimidine alternating oligomers by the Suzuki coupling reaction. The resultant oligomers could serve as an active electron transporting material in the OLED device.

A two-step synthesis of phenylene-pyrimidine alternating oligomers by a Pd-catalyzed cross-coupling reaction starting from 2-bromo-5-iodopyrimidine $\mathbf{1}$ is outlined in Scheme 1.

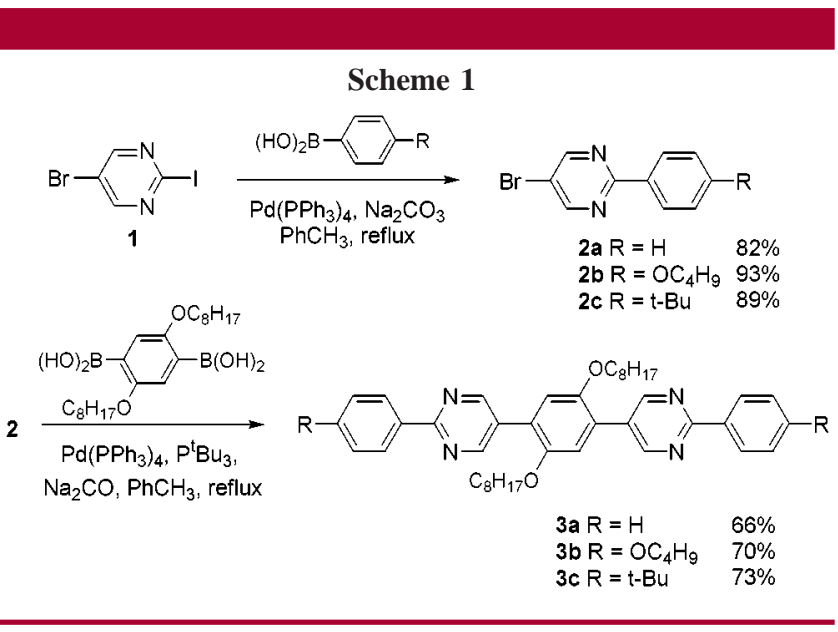

The selective coupling reaction of $\mathbf{1}^{18}$ on the iodo-substituted carbon with aryl boronic acids was carried out under standard aqueous Suzuki coupling conditions to afford $\mathbf{2 a}-\mathbf{c}$ in excellent yields. However, a second Suzuki coupling on the

(6) Naka, S.; Okada, H.; Onnagawa, H.; Tsutsui, T. Appl. Phys. Lett. 2000, 76, 197

(7) (a) Yamamoto, T.; Maruyama, T.; Zhou, Z.-H.; Ito, T.; Fukuda, A.; Kubota, K. J. Am. Chem. Soc. 1994, 116, 4832. (b) Wang, Y. Z.; Epstein, A. J. Acc. Chem. Res. 1999, 32, 217.

(8) Peng, Z.; Galvin, M. E. Chem. Mater. 1998, 10, 1785.

(9) Saito, N.; Kanbara, T.; Nakamura, Y.; Yamamoto, T.; Kubota, K. Macromolecules 1994, 27, 657.

(10) (a) Yamamoto, T.; Sugiyama, K.; Kushida, T.; Inoue, T.; Kanbara T. J. Am. Chem. Soc. 1996, 118, 3930. (b) Redecker, M.; Bradley, D. D. C.; Jandke, M.; Strohriegl, P. Appl. Phys. Lett. 1999, 75, 109.

(11) Tao, Y. T.; Balasubramaniam, E.; Danel, A.; Tomasik, P. Appl. Phys. Lett. 2000, 77, 933.

(12) (a) Tamao, K.; Uchida, M.; Izumizawa, T.; Furuukawa, K.; Yamaguchi, S. J. Am. Chem. Soc. 1996, 118, 11974. (b) Yamaguchi, S.; Endo, T.; Uchida, M.; Izumizawa, T.; Furukawa, K.; Tamao, K. Chem. Eur. J. 2000, 6, 1683 .

(13) Suh, M. C.; Jiang, B.; Tilley, T. D. Angew. Chem., Int. Ed. 2000, $39,2870$.

(14) Barbarella, G.; Favaretto, L.; Sotgiu, G.; Zambianchi, M.; Bongini, A.; Arbizzani, C.; Mastragositino, M.; Anni, M.; Gigli, G.; Cingolani, R. J. Am. Chem. Soc. 2000, 122, 11971.

(15) Burn, P. L.; Grice, A. W.; Tajbakhsh, A.; Bradley, D. D. C.; Thomas, A. C. Adv. Mater. 1997, 9, 1171

(16) Kanbara, T.; Kushida, T.; Saito, N.; Kuwajima, I.; Kubota, K.; Yamamoto, T. Chem. Lett. 1992, 583.

(17) Gommper, R.; Mair, H.-J.; Polborn, K. Synthesis 1997, 696. bromo-substituted carbon of $\mathbf{2}$ with diboronic acid was promoted by adding a bulky trialkyphosphine, $\mathrm{PB}_{3} \mathrm{Bu}_{3}$, as a cocatalyst. The corresponding oligomers $\mathbf{3 a}-\mathbf{c}$ were isolated in good yields and characterized with satisfactory spectral analyses. ${ }^{19}$

To investigate the electronic properties of the phenylenepyrimidine alternating oligomers, $\mathbf{3 a}-\mathbf{c}$, we first examined the absorption spectra for each oligomer in dilute solution $\left(\mathrm{CHCl}_{3}\right)$. The vacuum-deposited thin films of $\mathbf{3 a}-\mathbf{c}$ were also inspected for comparison. Two absorption bands were observed, which were red-shifted when compared to those of the analogous pentaphenylene. ${ }^{20}$ The resultant bathochromic shift is presumably due to the intramolecular charge transfer $^{21}$ in our oligomers with a donor-acceptor alternating arrangement. In the solid film, the relative intensity of the long wavelength absorption is increased and distinctly redshifted while the short wavelength absorption stays almost unchanged. The red-shifted absorption could result from the molecules with a more coplanar conformation in the solid film. The terminal substituents of oligomers $\mathbf{3} \mathbf{a}-\mathbf{c}$ have no substantial influences on the absorption wavelength; the oligomers terminated with electron-donating butoxy groups (3b) only exhibit a slightly bathochromic shift (ca. $17 \mathrm{~nm}$ ) in short wavelength absorption when compared to that of 3a. The $\lambda_{\max }$ for oligomers $\mathbf{3} \mathbf{a}-\mathbf{c}$ are summarized in Table 1.

Oligomers $\mathbf{3 a}-\mathbf{c}$ exhibit strong blue fluorescence in dilute solution with emission maximum centered at $419 \mathrm{~nm}$ irrespective of the nature of the terminal substituents. The quantum yields are $0.37,0.54$, and 0.37 for $\mathbf{3 a}, \mathbf{3 b}$, and $\mathbf{3 c}$, respectively. It is worth noting that, in the solid film, 3a and $\mathbf{3 b}$ exhibit PL spectra without a distinct red shift when compared to those in solution. The identity of the emission behavior suggests that the excited state of $\mathbf{3 a}$ and $\mathbf{3 b}$ could have a similar conjugation length in dilute solution and in the solid film. A comparison of the photoluminescence spectrum of $\mathbf{3 c}$ in solution and in the solid film is shown in Figure 1. For $\mathbf{3 c}$, the most intensive emission peaks in the solid film are almost overlapped with the emission peak in solution. In addition, three weak emission peaks at 461, 495, and $545 \mathrm{~nm}$ were also detected. The long wavelength emission peaks could be possibly attributed to the intermo-

(18) (a) Goodby, J. W.; Hird, M.; Lewis, R. A.; Toyne, K. J. Chem Commun. 1996, 2179. (b) During the preparation of this manuscript, the Suzuki coupling reaction of halogenated pyrimidne was reported: Schomaker, J. M.; Delia, T. J. J. Org. Chem. 2001, 66, 7125.

(19) Representative experimental procedure: Bisboronic acids (prepared by the literature method: Hu, Q.-S.; Huang, W.-S.; Vitharana, D.; Zheng, X.-F.; Pu, L. J. Am. Chem. Soc. 1997, 119, 12454) (422 mg, 1 mmol), 2 b (615 mg, $2.0 \mathrm{mmol}), \mathrm{Na}_{2} \mathrm{CO}_{3}\left(2.0 \mathrm{~mL}, 2 \mathrm{M}\right.$ in $\mathrm{H}_{2} \mathrm{O}, 4.0 \mathrm{mmol}$ ), $\mathrm{Pd}\left(\mathrm{PPh}_{3}\right)_{4}(23 \mathrm{mg}, 1 \mathrm{~mol} \%)$, and $\mathrm{P}^{\mathrm{t}} \mathrm{Bu}_{3}(0.2 \mathrm{~mL}, 0.05 \mathrm{M}$ in toluene, $5 \mathrm{~mol}$ $\%)$ in argon-saturated toluene $(10 \mathrm{~mL})$. The mixture was refluxed overnight under argon. The mixture was allowed to cool to room temperature and diluted with chloroform $(10 \mathrm{~mL})$. The organic solution was dried over $\mathrm{MgSO}_{4}$. The concentrated crude product was recrystallized from $\mathrm{CHCl}_{3}$ with $\mathrm{MeOH}$ to afford $\mathbf{3 b}$ as a light yellow solid (550 mg, 70\%) (for characterization data, see the Supporting Information).

(20) Zhao, M.; Cui, Y.; Samoc, M.; Prasad, P. N.; Unroe, M. R.; Reinhardt, B. A. J. Chem. Phys. 1991, 95, 3991.

(21) (a) Yamamoto, T.; Zhou, Z.-H, Kanbara, T.; Shimura, M.; Kizu, K. Maruyama, T.; Nakamura, Y.; Fukuda, T.; Lee, B.-L.; Ooba, N.; Tomaru, S.; Kurihara, T.; Kaino, T.; Kubota, K.; Sasaki, S. J. Am. Chem. Soc. 1996, 118, 10389. (b) Zhang, Q. T.; Tours, J. M. J. Am. Chem. Soc. 1998, 120, 5355 . 
Table 1. Physical Properties of Phenylene-Pyrimidine Alternating Oligomers 3a-c

\begin{tabular}{|c|c|c|c|c|c|c|c|c|}
\hline compound & $\lambda_{\max }{ }^{a}$ & $\lambda_{\max }{ }^{b}$ & enax $^{a}$ & $\theta_{\max }{ }^{b}$ & $\mathrm{E}_{\mathrm{pc}}^{1}, \mathrm{E}_{\mathrm{pa}}^{1} \mathrm{c}$ & $\mathrm{E}_{\mathrm{pc}}^{2}, \mathrm{E}_{\mathrm{pa}}^{2}$ & $\Delta \mathrm{E}(\mathrm{mV})^{\mathrm{d}}$ & $\mathrm{T}_{\mathrm{d}}\left({ }^{\circ} \mathrm{C}\right)^{\mathrm{f}}$ \\
\hline $3 a$ & 290,352 & 292,362 & 419 & 423 & $-2.00,-1.73$ & $-2.18,-1.91$ & 180 & 444 \\
\hline $3 b$ & 307,352 & 307, 392 & 419,430 & 417,434 & $-2.04,-1.77$ & $-2.21,-1.95$ & 170 & 457 \\
\hline $3 c$ & 296,352 & 299,370 & 419 & 410,428 & $-2.08,-1.83$ & $-2.28,-2.04$ & 200 & 441 \\
\hline
\end{tabular}

${ }^{a} \mathrm{In} \mathrm{nm}, 5.0 \times 10^{-5} \mathrm{M}$ in $\mathrm{CHCl}_{3} .{ }^{b} \mathrm{In} \mathrm{nm}$, vacuum deposited thin film. ${ }^{c} \mathrm{~V}$ vs $\mathrm{Ag} / \mathrm{AgCl}$ in THF with $\mathrm{n}-\mathrm{Bu}_{4} \mathrm{NClO}_{4}$ as a supporting electrolyte. ${ }^{d} \Delta E=E_{\mathrm{pc}}^{1}$ $-E_{\mathrm{pc}}^{2}{ }^{e}$ Detected by the DSC analysis of liquid $\mathrm{N}_{2}$ quenched melt sample, heating rate $=10{ }^{\circ} \mathrm{C} / \mathrm{min} .{ }^{f}$ Detected by TGA analysis.

lecular interactions occurring in the solid state or the formation of excimer.

Figure 2a provides views of the crystal packing diagram of 3a. The terminal phenyl ring and pyrimidine ring are in a coplanar plane (with angles between the least-squares planes of $<3.3^{\circ}$ ) due to the lack of ortho-ortho interactions, while the central phenyl ring is rotated by $42.5^{\circ}$ with respect to the pyrimidine ring. The $\mathbf{3 a}$ crystals stack each other in such a way that the coplanar phenyl-pyrimidine segments are closely lined up, but in opposite direction, with the same segment of the neighboring molecule. Although these coplanar segments could overlap to a large extent, the closest interatomic (least-squares interplane) distance between the terminal phenyl ring in one molecule and the pyrimidine ring in another molecule is calculated to be $3.49 \AA(3.55 \AA)$, which is expected to have intermolecular interactions. In contrast to 3a, 3c crystallized in a different manner. The crystal packing diagram for $\mathbf{3 c}$ is shown in Figure $2 \mathrm{~b}$. The five aryl rings of $\mathbf{3 c}$ are not coplanar to one another. The ${ }^{t} \mathrm{Bu}$-substituted phenyl ring is twisted by $-19.2^{\circ}$ to the adjacent pyrimidne ring, while the central phenyl ring is rotated by $25.2^{\circ}$ with respect to the pyrimidine ring. 3c stacks in such a way that the pyrimidine rings from different molecules are closely packed to one another as the dipolar orientation is in opposite direction. The crystal packing is driven by this dipole-dipole interaction between the pyrimidine rings. However, the packing between the terminal

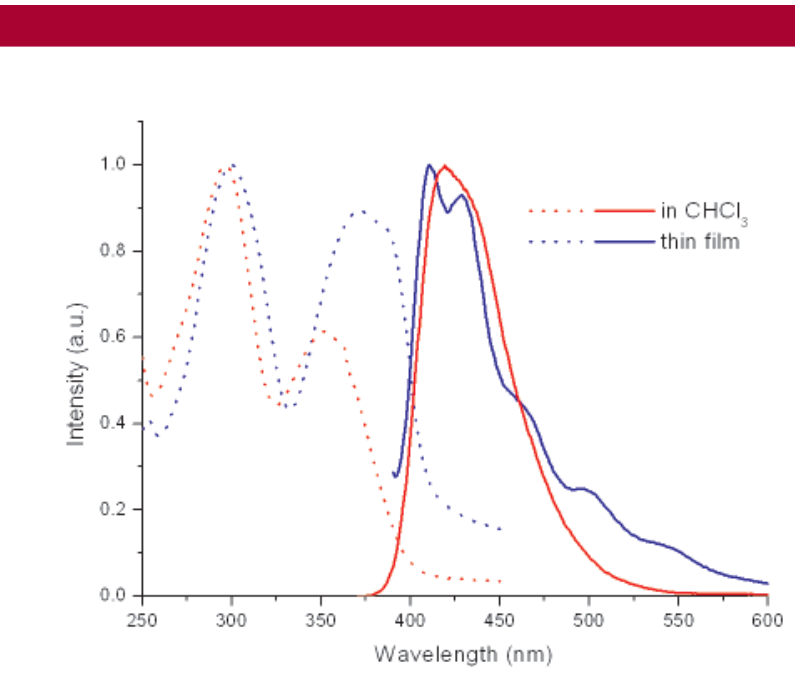

Figure 1. A comparison of the absorption and emission spectra of $3 \mathbf{c}$ in solution $\left(5.5 \times 10^{-5} \mathrm{M}\right.$ in $\left.\mathrm{CHCl}_{3}\right)$ and thin film. phenyl ring and the central phenyl ring may also contribute to the crystallization. Due to the large terminal groups in 3c, the weak intermolecular interactions are characterized by inspecting the shortest intermolecular contact distance, $3.66 \AA$, between the nitrogen in one molecule and the $\mathrm{C} 4$ carbon in the pyrimidine of neighboring molecule.

The electrochemical properties of oligomers $\mathbf{3 a}-\mathbf{c}$ were investigated by cyclic voltammetry in THF. The data are summarized in Table 1. Two quasi-reversible cathodic reduction couples were observed with the potential difference $\left(\Delta E=E_{\mathrm{pc}}^{1}-E_{\mathrm{pc}}^{2}\right) 180 \mathrm{mV}, 170 \mathrm{mV}$, and $200 \mathrm{mV}$ for $\mathbf{3 a}$, $\mathbf{3 b}$, and $\mathbf{3 c}$, respectively. These two reductions were believed to occur at the pyrimidine rings successively. The large potential difference between the two reductions indicates that the first radical anion, as it was formed, could efficiently delocalize along the $\pi$-conjugation in the molecule, resulting in the difficult formation of the dianion species. Figure 3 shows a comparison of the cyclic voltammogram of oligomers $\mathbf{3 a}-\mathbf{c}$. The electron-donating butoxy group in $\mathbf{3 b}$ slightly increased the first reduction potential by $0.08 \mathrm{~V}$ when compared to that of $\mathbf{3 a}$. 3c, with the less electron-donating ${ }^{t} \mathrm{Bu}$ groups, exhibits a reduction potential between that of $\mathbf{3 a}$ and $\mathbf{3 b}$. These results indicate that the pyrimidine moiety

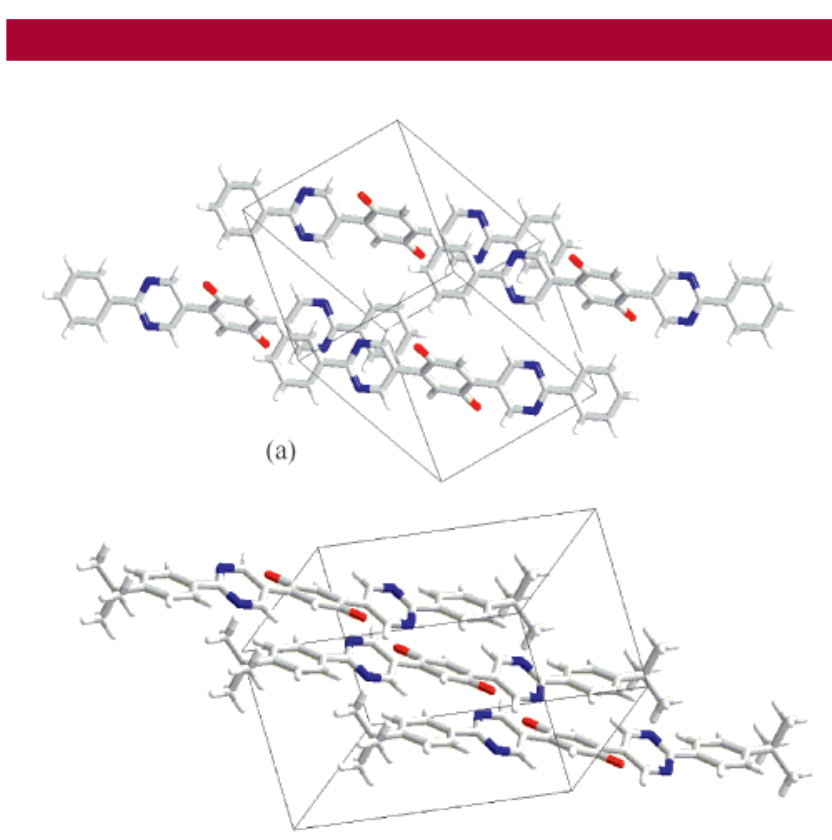

(b)

Figure 2. The molecular packing diagram of 3a (a) and $\mathbf{3 c}$ (b). The long octyl chains are omitted for clarity. 


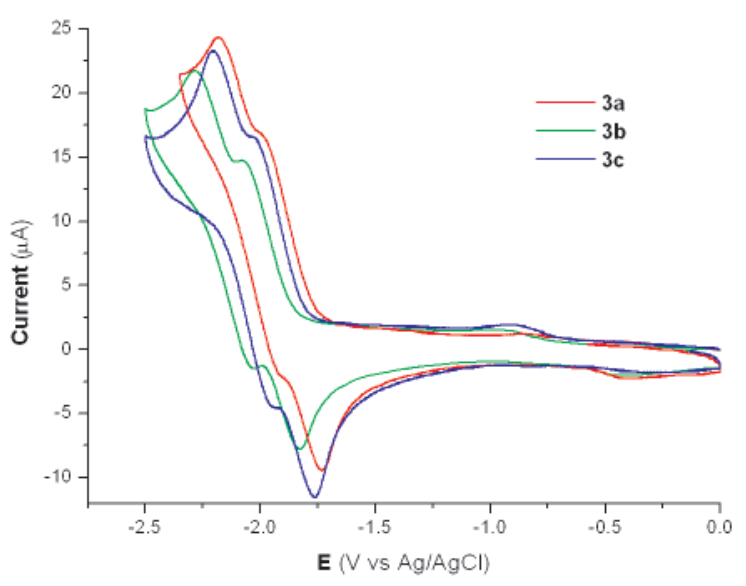

Figure 3. Cyclic voltammogram of $\mathbf{3 a}-\mathbf{c}$ in THF $\left(1.0 \times 10^{-3}\right.$ M).

could serve as a electron-accepting center once it was incorporated into a $\pi$-conjugated system. In addition, the reduction potential could be finely tuned by introducing substituents with different electronic nature at the terminal position.

The thermal property and the morphological stability of 3a-c were investigated by the TGA and DSC analysis, respectively. $\mathbf{3 a}-\mathbf{c}$ exhibited high thermal stability; the TG thermograms revealed that no weight loss was detected below $380{ }^{\circ} \mathrm{C}$ for $\mathbf{3 a}-\mathbf{c}$. The temperature corresponding to the completed weight loss of $\mathbf{3 a}-\mathbf{c}$ is summarized in Table 1. The DSC analysis of the liquid nitrogen quenched meltsamples of $\mathbf{3} \mathbf{a}-\mathbf{c}$ showed that only $\mathbf{3 a}$ and $\mathbf{3} \mathbf{c}$ exhibited a relatively low glass transition temperature $\left(T_{\mathrm{g}}\right)$ at 27.7 and $31.5^{\circ} \mathrm{C}$, respectively. DSC analysis also indicated that there were several phase transitions of $\mathbf{3 a}-\mathbf{c}$ before the crystalline sample completely melted. Oligomers $\mathbf{3 a}$ and $\mathbf{3 b}$ melt at 150.5 and $160.2{ }^{\circ} \mathrm{C}$, respectively, while 3c with bulky terminal groups showed a higher melting temperature at $194.7{ }^{\circ} \mathrm{C}$. The low $T_{\mathrm{g}}$ and low melting temperature are presumably due to the introduction of two octyloxyl side chains at the central phenylene ring as a solubilizing group.
We have studied the electroluminescent (EL) properties of these pyrimidine-containing oligomers. The typical device structure was ITO/PEDT-PSS (300 $) / \mathrm{NCB}(450 \AA) / 3 \mathbf{b}$ or 3c $(500 \AA) / \mathrm{Mg}: \mathrm{Ag}(10: 1) / \mathrm{Ag}$. It was found that $\mathbf{3 b}$ and $\mathbf{3 c}$ function well as the electron-transport layer in the device. It is consistent with the electrochemical results since it is found that these pyrimidine derivatives in general have a strong electron-accepting reduction tendency. Their electron affinities estimated from electrochemical results are about $3.0 \mathrm{eV}$, comparable or even slightly larger than that of Alq3, a widely used electron-transport material. Among the compounds studied (3b and $\mathbf{3 c}$ ), the $\mathbf{3} \mathbf{c}$ device exhibits substantially lower operation voltage than the $\mathbf{3 b}$ device (10 vs $15 \mathrm{~V}$ at 100 $\mathrm{cd} / \mathrm{m}^{2}$ ); this may be due to the higher morphological stability and lower reduction potential of $\mathbf{3 c}$. Oligomers $\mathbf{3 b}$ and $\mathbf{3 c}$ also function as efficient blue emitters in the devices, exhibiting blue EL similar to their PL with external EL quantum efficiencies of $1.3-1.8 \%$ (photon/electron) and brightness over $2000 \mathrm{~cd} / \mathrm{m}^{2}$. These results are rather encouraging since these devices are nondoped; optimization of device structures and material properties may further enhance the blue-emitting device performance.

In conclusion, a series of phenylene-pyrimidine alternating oligomers with interesting photophysical and electronic properties have been successfully synthesized using the Suzuki coupling reaction. Further modification of the central linkage by introducing a rigid skeleton for creating pyrimidine-containing glassy materials is currently under investigation and will be reported in due course.

Acknowledgment. We are grateful to the National Science Council and the Ministry of Education of Taiwan for financial support.

Supporting Information Available: ${ }^{1} \mathrm{H}$ and ${ }^{13} \mathrm{C}$ NMR spectra of $\mathbf{3 a}, \mathbf{3 b}$, and $\mathbf{3 c}$ and detailed experimental procedures, full characterization, X-ray crystallographic data (CIF) for 3a and 3c. UV-vis and PL spectra for 3a and 3b. OLED device characteristics of $\mathbf{3 b}$ and $\mathbf{3 c}$. This material is available free of charge via Internet at http://pubs.acs.org.

OL017066Z 